\title{
El papel de la escala en los patrones de variación del bacterioplancton en lagunas de alta montaña
}

\author{
Elvira Pulido-Villena ${ }^{1}$, Eva Ortega-Retuerta ${ }^{1}$, Rafael Morales-Baquero ${ }^{2}$ e Isabel Reche ${ }^{2}$ \\ ${ }^{1}$ Dpto. de Biología Animal y Ecología, Universidad de Granada. 18071 Granada, España \\ ${ }^{2}$ Instituto del Agua, Universidad de Granada. 18071 Granada, España
}

\section{RESUMEN}

En todos los ecosistemas, los patrones de variación de sus componentes y procesos dependen de la escala de estudio. El bacterioplancton es un componente de las redes tróficas pelágicas cuyos patrones de variación entre sistemas y dentro de un mismo sistema a lo largo del tiempo han sido minuciosamente estudiados. En este estudio, se exploró el efecto de la escala sobre los patrones de variación del bacterioplancton en lagunas de alta montaña. Se consideraron dos descriptores del bacterioplancton (abundancia $(\mathrm{AB})$ y producción (PB)), y sus potenciales mecanismos de control por los recursos en una laguna a lo largo del período libre de hielo (considerada aquí escala local) y en un conjunto de lagunas que reflejan la heterogeneidad del área de estudio (considerada aquí escala regional). A escala regional, tanto los descriptores del bacterioplancton como sus potenciales mecanismos de control mostraron una mayor variabilidad que a escala local, excepto para la concentración de hierro disuelto. A escala regional, la PB se relacionó con la concentración de fósforo total, sin embargo, esta dependencia no se observó con la $\mathrm{AB}$ ni a la escala local. Estos resultados indican que, en las lagunas de Sierra Nevada, los dos descriptores del bacterioplancton tuvieron un comportamiento diferente y que el cambio de escala implicó diferentes patrones de variación. Por lo tanto, en estudios limnológicos, para poder extrapolar patrones del bacterioplancton entre escalas es necesario utilizar los mismos descriptores y garantizar que están actuando los mismos mecanismos de control.

Palabras clave: escala, patrones, control por recursos, bacterioplancton, lagos de alta montaña

\begin{abstract}
In all ecosystems, variability patterns of components and processes depend on the scale of study. Bacterioplankton is a component of pelagic food webs whose variability patterns across systems and within one system over time have been thoroughly studied. In this study, the effect of scale on variability patterns of bacterioplankton in high mountain lakes was studied. Two bacterioplankton descriptors (bacterial abundance (AB) and production PB)) and their potential control mechanisms by resources were considered within one lake during the ice free period (considered here as local scale) and in a set of lakes that reflect the heterogeneity of the study area (considered here as regional scale). At the regional scale, both bacterioplankton descriptors and their potential control mechanisms showed a higher variability than at local scale, except for dissolved iron. At the regional scale, $P B$ was related to total phosphorus concentration, however, this dependence was not observed with $A B$ nor at local scale. These results point out that, in Sierra Nevada lakes, bacterioplankton descriptors showed different behavior and that the change in scale involved different variability patterns. Therefore, in limnological studies, to extrapolate bacterioplankton patterns among scales, it is necessary to use the same descriptors and to guarantee that the same control mechanisms are operating.
\end{abstract}

Keywords: scale, patterns, resources control, bacterioplankton, high mountain lakes

\section{INTRODUCCIÓN}

En el estudio de los ecosistemas, el concepto de patrón de variación está estrechamente ligado al de escala (Hutchinson, 1953), ya que los mecanismos de control que lo determinan pueden cambiar en función de la escala de estudio. Es necesario, por lo tanto, conocer qué mecanismos de control son independientes de la escala y cuales no para poder extrapolar patrones de variación entre escalas (Levin, 1992).

Dentro de los ecosistemas acuáticos, la importancia del bacterioplancton determina la contribución potencial del bucle microbiano a 
la red trófica general y, en consecuencia, la magnitud del flujo de carbono desde la materia orgánica disuelta a los niveles tróficos superiores (Azam et al., 1983; Cole, 1999). El bacterioplancton, además, consume y/o regenera nitrógeno, fósforo y oligoelementos (p.e. hierro), afectando a los ciclos de nutrientes (Goldman et al., 1987; Currie, 1990; Vadstein et al., 1993; Tortell et al., 1996). Dada la importancia del bacterioplancton en los ecosistemas acuáticos, sus patrones de variación a diferentes escalas han sido minuciosamente estudiados (Currie, 1990; Shiah \& Ducklow, 1995).

Existen numerosos mecanismos de control que determinan los patrones de variación de la abundancia y producción del bacterioplancton: condiciones físicas (radiación y temperatura), disponibilidad de recursos nutritivos (control bottom-up) y mecanismos bióticos como la depredación o la infección viral (control topdown) (McManus \& Furhman, 1988; Kirchman, 1990, 1994; Fuhrman \& Suttle, 1993; Pace \& Cole, 1994; Shiah \& Ducklow, 1994; Felip et al., 1996; Gasol \& Duarte, 2000). Entre las condiciones físicas, numerosos estudios han demostrado que la temperatura controla la abundancia, producción y tasas de crecimiento del bacterioplancton (White et al. 1991, Shiah \& Ducklow, 1994). Otros estudios más recientes han explorado el efecto negativo de la radiación UV sobre el crecimiento y la actividad bacteriana (Sommaruga et al., 1997, 1999). El control del bacterioplancton por los recursos es especialmente importante en ecosistemas oligotróficos, mientras que en sistemas eutróficos el bacterioplancton parece estar más controlado por la depredación (Sanders et al., 1992). Entre los recursos responsables del control del bacterioplancton, numerosos trabajos destacan la importancia del carbono orgánico disuelto y el fósforo (Cole et al., 1988; Currie, 1990; Ducklow, 1992). Más recientemente, se ha explorado el papel del hierro en la limitación del crecimiento bacteriano, sobretodo en ecosistemas marinos (Tortell et al., 1996; Church et al., 2000; Kirchman et al., 2000). La importancia relativa de las condiciones físicas y los recursos nutriti- vos como mecanismos de control del bacterioplancton depende, en parte, de la escala de estudio (Currie, 1990; Shiah \& Ducklow, 1995). Los estudios entre varios sistemas realizados a gran escala han mostrado que la abundancia y producción del bacterioplancton están controladas fundamentalmente por los recursos, si bien no está del todo claro si esta dependencia se mantendría a escalas menores. Por otro lado, las variaciones temporales en la abundancia y producción bacterianas dentro de un mismo sistema parecen estar controladas principalmente por la temperatura y en menor grado por la disponibilidad de recursos (Shiah \& Ducklow, 1994, 1995).

Los lagos de alta montaña están situados por encima de la línea de árboles y tienen pequeñas cuencas de captación con suelos pobres y escasa vegetación. Por lo tanto, estos ecosistemas son, normalmente, oligotróficos ya que reciben pocos aportes de nutrientes tanto minerales como orgánicos (Baron et al., 1991; MoralesBaquero et al., 1999; Sommaruga et al., 1999; Reche et al., 2001). Este hecho sitúa, probablemente, a los recursos nutritivos como los principales mecanismos de control del bacterioplancton en estos sistemas. En este tipo de ecosistemas, la biota está sometida a condiciones físicas extremas, tales como bajas temperaturas y elevada radiación ultravioleta incidente (Caldwell et al., 1980). Hasta la fecha, los estudios sobre bacterioplancton en lagos de alta montaña son escasos (Reche et al. 1996; Wille et al. 1999), por lo que sus patrones de variación y sus mecanismos de control no están aún totalmente definidos a las diferentes escalas. En particular, las lagunas de Sierra Nevada tienen un origen glaciar y están situadas a alturas comprendidas entre 2800 y 3100 m.s.n.m., por encima de la línea de árboles. Son de pequeño tamaño, escasa profundidad y están cubiertas de hielo durante 8-9 meses al año. Más allá de estas características comunes, existe una gran variabilidad en sus cuencas de captación (tamaño, presencia de borreguiles, arroyos de entrada y/o salida), lo que otorga una importante heterogeneidad regional (MoralesBaquero et al., 1999). 
Tabla 1. Localización, características de la cuenca, morfometría y concentración de clorofila-a de las lagunas de estudio ( ${ }^{1}$ Datos de Morales-Baquero et al. 1999; ${ }^{2}$ Heterogeneidad regional: B: rodeada parcialmente por borreguiles; R: terreno rocoso; ES: presencia de arroyos de entrada y/o salida; n.d.: no disponible). Location, catchment characteristics, morphometry and chlorophyll-a concentration of study lakes ( ${ }^{1}$ Data from Morales-Baquero et al. 1999; ${ }^{2}$ Regional heterogeneity: B: partially surrounded by meadows; R: rocky terrain; ES: presence of inlets and/or outlets; n.d.: not available).

\begin{tabular}{|c|c|c|c|c|c|c|c|}
\hline Laguna & $\begin{array}{l}\text { Localización } \\
\text { UTM }(30 S)^{1}\end{array}$ & $\begin{array}{c}\text { Altitud } \\
(\mathrm{m} \text { s.n.m. })^{1}\end{array}$ & $\begin{array}{c}\text { Área de } \\
\text { captación }(\mathrm{ha})^{1}\end{array}$ & $\begin{array}{l}\text { Heterogeneidad } \\
\text { regional }^{2}\end{array}$ & $\begin{array}{c}\text { Superficie } \\
\text { (ha) }^{1}\end{array}$ & $\begin{array}{l}\text { Profundidad } \\
\text { máxima }(m)^{1}\end{array}$ & $\begin{array}{c}\text { Clorofila } \\
(\mu \mathrm{g} / \mathrm{l})^{1}\end{array}$ \\
\hline Río Seco (RS) & VG694009 & 3020 & 9.9 & $\mathrm{~B} / \mathrm{ES}$ & 0.42 & 2.0 & 0.5 \\
\hline Caldera (CA) & VG708012 & 3050 & 23.5 & $\mathrm{R}$ & 2.10 & 7.0 & 0.2 \\
\hline Aguas Verdes (AV) & VG674006 & 3050 & 12.8 & $\mathrm{~B} / \mathrm{ES}$ & 0.19 & 2.8 & 0.6 \\
\hline Yeguas (YE) & VG662013 & 2880 & 50.0 & $\mathrm{R}$ & 0.33 & 2.5 & 2.2 \\
\hline Virgen Superior (VS) & VG665008 & 2950 & 25.1 & $\mathrm{~B}$ & 0.08 & 1.3 & 0.4 \\
\hline Virgen Media (VM) & VG664009 & 2940 & 31.2 & $\mathrm{~B}$ & 0.01 & 0.8 & 2.2 \\
\hline Laguna 2 (L2) & VG735014 & 3020 & 27.4 & $\mathrm{~B}$ & 0.34 & 3.5 & 0.5 \\
\hline Laguna 4 (L4) & VG737012 & 2970 & 57.1 & $\mathrm{~B}$ & 0.19 & 0.4 & 0.7 \\
\hline Laguna 5 (L5) & VG734009 & 2980 & 50.9 & $\mathrm{~B}$ & 0.18 & 2.0 & 1.7 \\
\hline Hondera (HO) & VG739004 & 2890 & 154. 6 & $\mathrm{~B} / \mathrm{ES}$ & 0.53 & 0.8 & 0.8 \\
\hline Peñón Negro (PN) & VF738983 & 2820 & 28.2 & $\mathrm{~B}$ & 0.67 & 2.0 & 4.1 \\
\hline
\end{tabular}

En este trabajo se exploraron los patrones de variación del bacterioplancton de las lagunas de Sierra Nevada a escala regional (analizando un conjunto de lagunas que reflejan la heterogeneidad de Sierra Nevada), y a escala local (estudiando una sola laguna a lo largo de todo el período libre de hielo), para evaluar si los recursos (mecanismos de control bottom-up) controlaron los patrones de variación del bacterioplancton y si este control se mantenía a las dos escalas consideradas.

\section{MATERIAL Y MÉTODOS}

\section{Lagos de estudio y muestreo}

Para el estudio del bacterioplancton a escala regional se seleccionaron once lagunas que reflejan la heterogeneidad del área de estudio: La Caldera (CA) y Las Yeguas (YE) están situadas sobre terreno rocoso desnudo; Río Seco (RS), Aguas Verdes (AV), Virgen Superior (VS), Virgen Media (VM), Laguna 2 (L2), Laguna 4 (L4), Laguna 5 (L5), Hondera (HO), y Peñón Negro (PN) están rodeadas por borreguiles; RS, AV, y HO presentan, además, arroyos de entrada y/o salida. Estas lagunas presentan un amplio rango en el tamaño de sus cuencas de captación (Tabla 1). El período de muestreo se redujo tanto como fue posible (4 días) para minimizar el efecto de la variación temporal. Cada laguna se muestreó una vez durante el período libre de hielo de 2000 y se tomaron muestras integradas del perfil vertical para analizar la concentración de carbono orgánico disuelto (COD), fósforo total (PT) e hierro disuelto $(\mathrm{FeD})$, y para determinar la abundancia (AB) y producción (PB) del bacterioplancton.

El estudio del bacterioplancton a escala local se realizó analizando la dinámica de los descriptores del bacterioplancton (AB y $\mathrm{PB}$ ) en la laguna de La Caldera durante el período libre de hielo de 2000. Esta laguna se muestreó semanalmente e, igualmente, se tomaron muestras integradas del perfil vertical para determinar la concentración de COD, PT y FeD.

\section{Análisis químicos y biológicos}

La abundancia bacteriana se determinó mediante microscopía de epifluorescencia después de teñir submuestras de 2 o $4 \mathrm{ml}$ con DAPI (Porter \& Feig, 1980). Se contaron al menos 400 células en 30 campos elegidos al azar. La producción bacteriana fue estimada a partir de la síntesis de proteínas siguiendo el método de centrifugación 
propuesto por Smith \& Azam (1992). Los valores de PB en términos de incorporación de leucina (pmol Leu $\mathrm{l}^{-1} \mathrm{~h}^{-1}$ ) fueron convertidos a unidades de cel $\mathrm{l}^{-1} \mathrm{~h}^{-1}$ mediante un factor de conversión, específico para cada laguna, calculado a partir de la concentración de COD (PulidoVillena \& Reche, 2003). La conversión de los valores de producción celular a unidades de carbono se realizó mediante un factor de conversión de $20 \mathrm{fg} \mathrm{C} / \mathrm{cel}$ (Lee \& Fuhrman, 1987).

El carbono orgánico disuelto fue analizado por duplicado filtrando agua de las lagunas a través de filtros Whatman $\mathrm{GF} / \mathrm{F}$ previamente sometidos a combustión $\left(>2 \mathrm{~h}\right.$ a $\left.500^{\circ} \mathrm{C}\right)$. El filtrado se recogió en frascos previamente sometidos a combustión, se acidificó con $\mathrm{HCl}$ hasta $\mathrm{pH}<2$ (para eliminar el carbono inorgánico) y se guardó a $4^{\circ} \mathrm{C}$ hasta el momento de su análisis. La concentración de COD fue determinada mediante oxidación catalítica a alta temperatura en un analizador Shimadzu TOC (Modelo 5000) equipado con un catalizador de cuarzo platinizado especial para análisis de alta sensibilidad (Benner \& Strom, 1993). El fósforo total fue analizado por duplicado como fósforo reactivo soluble según el método de Murphy \& Riley (1962) tras digestión en autoclave a $121^{\circ} \mathrm{C}$ durante $30 \mathrm{~min}$. El análisis de hierro disuelto fue realizado mediante absorción atómica en un horno de grafito previa filtración de las muestras a través de filtros Whatman GF/F.

\section{Análisis estadísticos}

Todas las variables fueron normalizadas mediante transformación logarítmica. Para evaluar el control del bacterioplancton por los recursos se realizaron correlaciones de Pearson entre los parámetros bacterianos y la concentración de COD, PT y FeD. En todas las correlaciones se aplicó la corrección de Bonferroni.

\section{RESULTADOS}

\section{Escala regional}

Los descriptores del bacterioplancton (AB y $\mathrm{PB}$ ) mostraron amplios rangos de variación a esta escala. $\mathrm{La} A B$ varió más de un orden de magnitud entre $0.6 \cdot 10^{6} \mathrm{cel} / \mathrm{ml}(\mathrm{HO})$ y $10.2 \cdot 10^{6} \mathrm{cel} / \mathrm{ml}$ (AV) y los valores obtenidos para la $\mathrm{PB}$ variaron más de dos órdenes de magnitud desde $3.3 \mathrm{pmol}$ leu $\mathrm{1}^{-1} \mathrm{~h}^{-1}$ (YE) hasta 687.4 pmol leu $\mathrm{l}^{-1} \mathrm{~h}^{-1}$ (L2) (Tabla 2). No se observó una correlación entre ambos descriptores.

Tabla 2. Valores medios ( \pm desviación estándar) de los descriptores del bacterioplancton (abundancia (AB) y producción (PB)) y concentración media ( \pm desviación estándar) de los recursos considerados como potenciales mecanismos de control del bacterioplancton (fósforo total (PT), hierro disuelto (FeD) y carbono orgánico disuelto (COD)) en las lagunas incluidas en el estudio a escala regional. Mean values ( \pm standard deviation) of bacterioplankton descriptors (abundance $(A B)$ and production $(P B)$ ) and mean ( \pm standard deviation) concentration of resources considered as potential control mechanisms of bacterioplankton (total phosphorus (PT), dissolved iron (FeD), and dissolved organic carbon (COD)), the lakes included in regional scale study.

\begin{tabular}{|c|c|c|c|c|c|}
\hline Laguna & $\begin{array}{c}\mathrm{AB} \\
\left(\cdot 10^{6} \mathrm{cel} / \mathrm{ml}\right)\end{array}$ & $\begin{array}{c}\text { PB } \\
\left(p m o l ~ l e u ~ l^{-1} h^{-1}\right)\end{array}$ & $\begin{array}{c}\text { PT } \\
(\mu \mathrm{M})\end{array}$ & $\begin{array}{c}\text { FeD } \\
(\mu \mathrm{M})\end{array}$ & $\begin{array}{l}\text { COD } \\
(\mu M)\end{array}$ \\
\hline RS & $4.1 \pm 0.0$ & $24.8 \pm 1.5$ & $0.47 \pm 0.02$ & 0.52 & $119 \pm 2$ \\
\hline $\mathrm{CA}$ & $0.9 \pm 0.1$ & $10.7 \pm 0.4$ & $0.08 \pm 0.01$ & 0.08 & $113 \pm 2$ \\
\hline $\mathrm{AV}$ & $10.2 \pm 0.6$ & $83.2 \pm 3.0$ & $0.59 \pm 0.04$ & 1.31 & $102 \pm 0$ \\
\hline YE & $3.9 \pm 0.1$ & $3.3 \pm 1.7$ & $0.04 \pm 0.02$ & 0.13 & $78 \pm 5$ \\
\hline VS & $1.4 \pm 0.1$ & $392.5 \pm 3.9$ & $0.17 \pm 0.04$ & 0.21 & $47 \pm 1$ \\
\hline VM & $2.2 \pm 0.1$ & $373.3 \pm 28.0$ & $0.76 \pm 0.01$ & 1.19 & $223 \pm 2$ \\
\hline L2 & $2.8 \pm 0.2$ & $687.4 \pm 21.0$ & $1.10 \pm 0.03$ & 0.73 & $300 \pm 6$ \\
\hline L4 & $2.2 \pm 0.1$ & $115.8 \pm 5.0$ & $0.24 \pm 0.19$ & 0.57 & $75 \pm 1$ \\
\hline L5 & $1.9 \pm 0.0$ & $98.3 \pm 33.5$ & $0.43 \pm 0.02$ & 0.67 & $91 \pm 11$ \\
\hline $\mathrm{HO}$ & $0.6 \pm 0.1$ & $162.7 \pm 30.4$ & $0.30 \pm 0.02$ & 0.37 & $47 \pm 2$ \\
\hline $\mathrm{PN}$ & $2.7 \pm 0.0$ & $391.4 \pm 38.5$ & $1.18 \pm 0.02$ & 1.14 & $106 \pm 1$ \\
\hline
\end{tabular}


Tabla 3. Coeficientes de correlación de Pearson entre los descriptores del bacterioplancton y los recursos a escala regional $(* * * \mathrm{p}<0.001 ; * * \mathrm{p}<0.01 ; * \mathrm{p}<0.05)$. Todas las variables están transformadas logarítmicamente. Pearson correlation coefficients between bacterioplankton descriptors and resources at regional scale $(* * *<0.001 ; * * p<0.01 ; * p<0.05)$. All variables are log-transformed.

\begin{tabular}{llll}
\hline & \multicolumn{1}{c}{ PT } & COD & FeD \\
\hline AB & 0.269 & 0.476 & 0.349 \\
PB & $0.780^{* *}$ & 0.223 & $0.654^{*}$ \\
PT & & 0.519 & $0.910^{* * *}$ \\
COD & & & 0.409 \\
\hline
\end{tabular}

Los recursos seleccionados en este estudio como posibles mecanismos de control del bacterioplancton (COD, PT y FeD) mostraron amplios rangos de variación entre los sistemas estudiados. La concentración de COD varió desde $47 \mu \mathrm{M}$ (VS, HO) hasta $300 \mu \mathrm{M}$ (L2), los valores de concentración de PT variaron casi dos órdenes de magnitud desde $0.04 \mu \mathrm{M}$ hasta $1.18 \mu \mathrm{M}$ y la concentración de FeD varió desde $0.08 \mu \mathrm{M}$ hasta $1.31 \mu \mathrm{M}$ (Tabla 2).

La Tabla 3 muestra los resultados de los análisis de correlación realizados entre los descriptores del bacterioplancton (AB y $\mathrm{PB}$ ) y los recursos. La $\mathrm{PB}$ estuvo significativamente correlacionada con la concentración de PT y de FeD. La AB no mostró ninguna correlación con estos recursos.

\section{Escala local}

La Tabla 4 muestra los valores de los descriptores del bacterioplancton (AB y $\mathrm{PB}$ ) y de la concentración de recursos (PT, COD, y FeD) en la laguna de La Caldera a lo largo del período libre de hielo.

Los rangos de variación de la abundancia y producción del bacterioplancton a esta escala fueron más estrechos que a escala regional (Fig. 1). A lo largo de todo el período libre de hielo, la $\mathrm{AB}$ en $\mathrm{La}$ Caldera osciló entre $0.5 \cdot 10^{6} \mathrm{cel} / \mathrm{ml}$ y $1.5 \cdot 10^{6}$

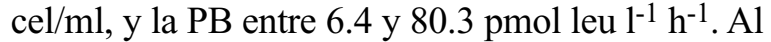
igual que en el estudio a escala regional, la variabilidad de la PB fue mayor que la de la AB.

La variación de la concentración de COD y de PT también fue menor que a escala regional (Fig. 2). La concentración de COD varió desde $44.8 \mu \mathrm{M}$ hasta $113.1 \mu \mathrm{M}$ y los valores de concentración de PT oscilaron entre $0.08 \mu \mathrm{M}$ hasta $0.35 \mu \mathrm{M}$. Sin embargo, la variación de la concentración de FeD a esta escala (desde $0.02 \mu \mathrm{M}$ hasta $0.4 \mu \mathrm{M}$ ) fue similar a la observada a escala regional (Fig. 2).

No se observó ninguna correlación significativa entre la abundancia o la producción del bacterioplancton y la concentración de PT. La concentración de COD y de FeD tampoco explicaron la variabilidad temporal de ninguno de estos descriptores.

Tabla 4. Valores medios ( \pm desviación estándar) de los descriptores del bacterioplancton (abundancia $(\mathrm{AB})$ y producción $(\mathrm{PB}))$ y concentración media ( \pm desviación estándar) de los recursos considerados como potenciales mecanismos de control del bacterioplancton (fósforo total (PT), hierro disuelto (FeD) y carbono orgánico disuelto (COD)) en la laguna de La Caldera a lo largo del período libre de hielo (n.d. no disponible). Mean values ( \pm standard deviation) of bacterioplankton descriptors (abundance $(A B)$ and production (PB)) and mean $( \pm$ standard deviation) concentration of resources considered as potential control mechanisms of bacterioplankton (total phosphorus (PT), dissolved iron ( $F e D)$, and dissolved organic carbon (COD)) in La Caldera lagoon through ice-free period (n.d. not available).

\begin{tabular}{|c|c|c|c|c|c|}
\hline Fecha & $\begin{array}{c}\mathrm{AB} \\
\left(\cdot 10^{6} \mathrm{cel} / \mathrm{ml}\right)\end{array}$ & $\begin{array}{c}\text { PB } \\
\left(\text { pmol leu } \mathrm{l}^{-1} \mathrm{~h}^{-1}\right)\end{array}$ & $\begin{array}{c}\text { PT } \\
(\mu \mathrm{M})\end{array}$ & $\begin{array}{c}\text { FeD } \\
(\mu \mathrm{M})\end{array}$ & $\begin{array}{l}\text { COD } \\
(\mu \mathrm{M})\end{array}$ \\
\hline $18 / 07 / 00$ & n.d. & n.d. & $0.20 \pm 0.05$ & 0.02 & $45 \pm 2$ \\
\hline $25 / 07 / 00$ & n.d. & n.d. & $0.35 \pm 0.07$ & 0.16 & $30 \pm 3$ \\
\hline $01 / 08 / 00$ & $1.1 \pm 0.0$ & $11.2 \pm 0.2$ & $0.25 \pm 0.02$ & 0.05 & $47 \pm 2$ \\
\hline $08 / 08 / 00$ & $0.9 \pm 0.1$ & $10.7 \pm 0.4$ & $0.08 \pm 0.01$ & 0.08 & $113 \pm 2$ \\
\hline $15 / 08 / 00$ & $1.5 \pm 0.1$ & $14.8 \pm 7.2$ & $0.09 \pm 0.01$ & 0.20 & $55 \pm 3$ \\
\hline $22 / 08 / 00$ & $0.8 \pm 0.0$ & $9.2 \pm 0.4$ & $0.12 \pm 0.00$ & 0.19 & $58 \pm 6$ \\
\hline $29 / 08 / 00$ & $0.7 \pm 0.0$ & $80.3 \pm 1.2$ & $0.17 \pm 0.00$ & 0.20 & $46 \pm 1$ \\
\hline $12 / 09 / 00$ & $0.5 \pm 0.0$ & $36.0 \pm 1.7$ & $0.11 \pm 0.00$ & n.d. & 33 \\
\hline $26 / 09 / 00$ & $0.5 \pm 0.0$ & $13.6 \pm 4.0$ & $0.17 \pm 0.04$ & 0.33 & $221 \pm 7$ \\
\hline $06 / 10 / 00$ & $0.6 \pm 0.1$ & $6.4 \pm 2.3$ & $0.10 \pm 0.00$ & 0.41 & $83 \pm 1$ \\
\hline
\end{tabular}



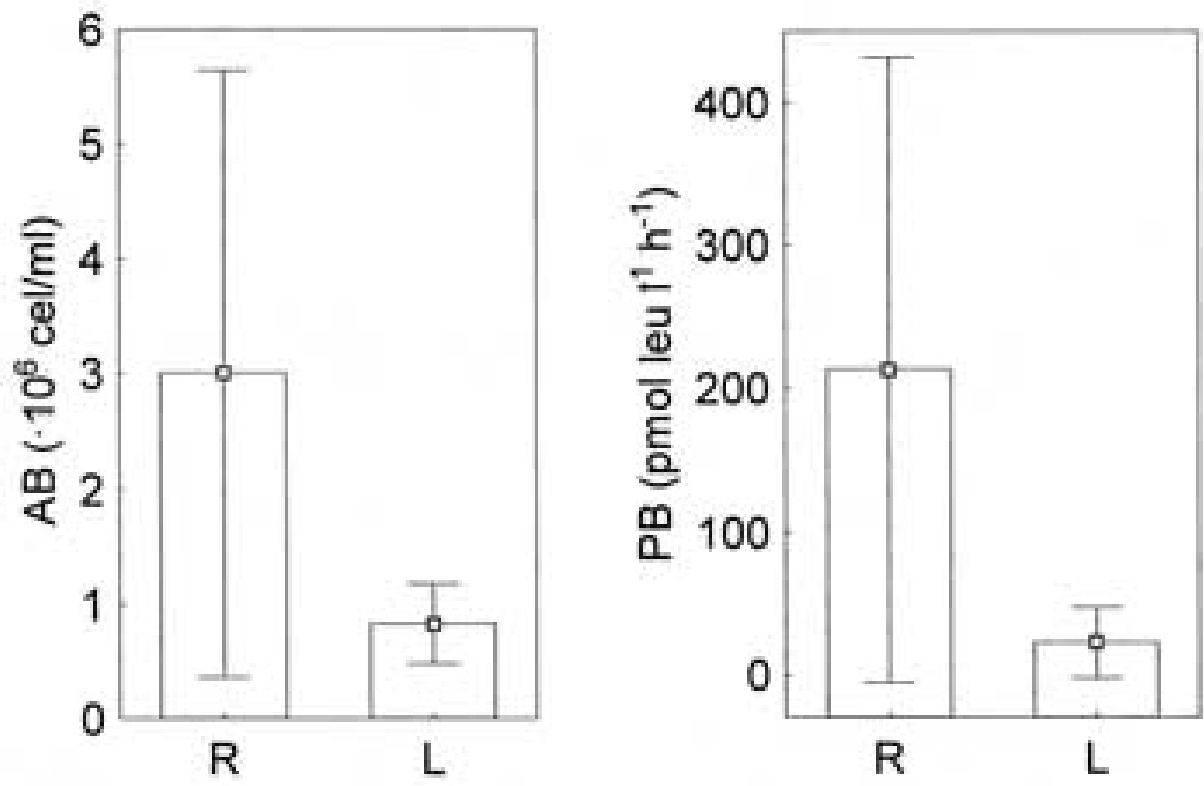

Figura 1. Media ( \pm desviación estándar) de los descriptores del bacterioplancton (abundancia $(\mathrm{AB})$ y producción $(\mathrm{PB}))$ a escala regional $(\mathrm{R})$ y local $(\mathrm{L})$. Mean ( \pm standard deviation) of bacterioplankton descriptors (abundance (AB) and production (PB)) at regional $(R)$ and local $(L)$ scale.

\section{DISCUSION}

La mayoría de los trabajos publicados hasta la fecha han estudiado los patrones de variación de la abundancia y producción del bacterioplancton a escalas que incluyen un gran número de sistemas localizados en paisajes muy diferentes entre sí (Cole et al., 1988; Currie, 1990; Pace \& Cole, 1994; Nurnberg \& Shaw, 1999). En este estudio la escala utilizada fue menor y corresponde a una zona, las cumbres de Sierra Nevada, cuyas características paisajísticas son, aparentemente, más homogéneas. A pesar de esto, se observó una gran variabilidad tanto en los descriptores del bacterioplancton (AB y $\mathrm{PB}$ ) como en los recursos seleccionados como potenciales mecanismos de control (PT, COD, FeD). Los valores de AB y $\mathrm{PB}$ obtenidos en este estudio son similares a los encontrados en otros lagos de alta montaña (Hinder et al., 1999, Wille et al., 1999, Sommaruga et al., 1997). Los valores de PB más bajos (3.3 y 10.4 pmol leu 1-1 $\mathrm{h}^{-1}$ ) corresponden a las dos lagunas situadas sobre terreno rocoso (CA y YE) que, probable- mente, reciben menos aportes de nutrientes minerales y orgánicos por lo que se encuentran bajo condiciones extremas de limitación.

La concentración de COD varió casi un orden de magnitud y los valores son similares a los observados en otros sistemas de alta montaña (Baron et al., 1991; Sommaruga et al., 1997). La concentración de PT varió más de un orden de magnitud, mostrando algunas lagunas valores más propios de sistemas mesotróficos (Wetzel, 1981), y la concentración de FeD varió, también, más de un orden de magnitud. La gran variabilidad observada tanto en los recursos como en los descriptores del bacterioplancton refleja la existencia de una considerable heterogeneidad dentro de este área de estudio.

En este estudio, el rango de variación de la $\mathrm{PB}$ fue mayor que el de la $\mathrm{AB}$ en las dos escalas consideradas. La PB se estimó a partir de la incorporación de leucina en proteínas. Bajo condiciones adversas como, por ejemplo, las existentes en las lagunas de Sierra Nevada (bajas temperaturas, elevada RUV, limitación por recursos) el bacterioplancton suele destinar 

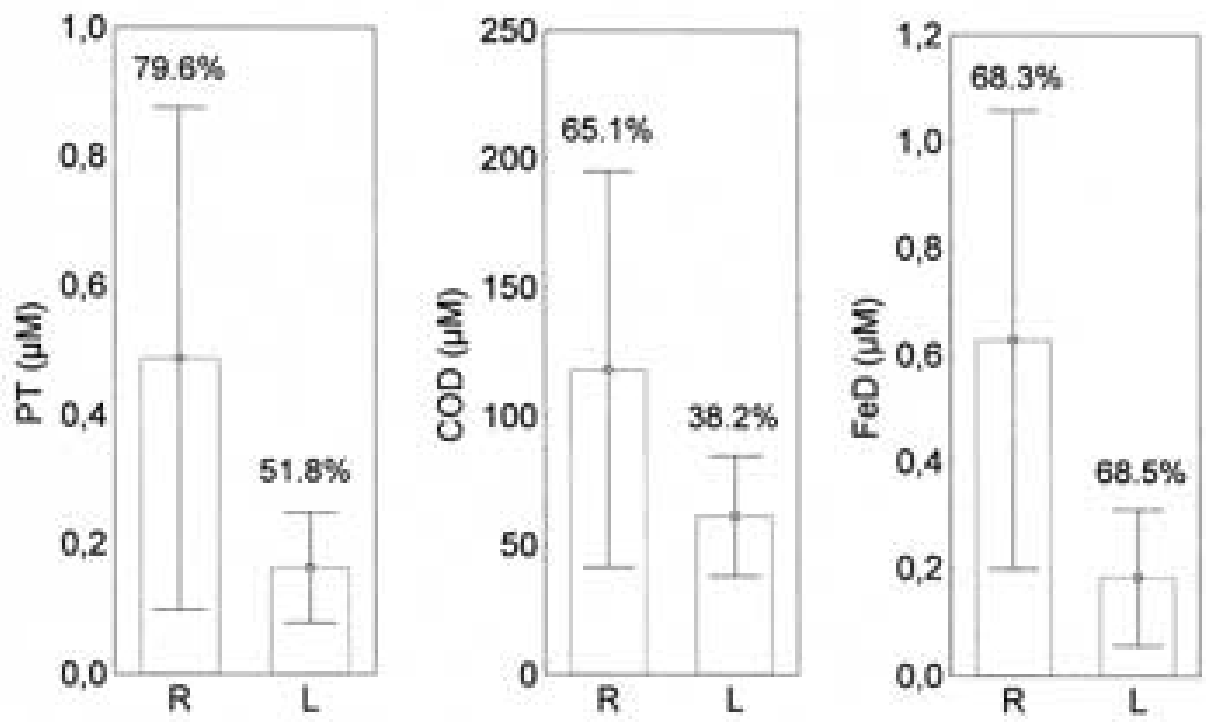

Figura 2. Media ( \pm desviación estándar) de la concentración de los recursos considerados como potenciales mecanismos de control del bacterioplancton (fósforo total (PT), carbono orgánico disuelto (COD) e hierro disuelto (FeD)) a escala regional (R) y local (L). Los porcentajes sobre las barras de desviación estándar son los valores del coeficiente de variación. Mean ( \pm standard deviation) concentration of resources considered as potential control mechanisms of bacterioplankton (total phosphorus (PT), dissolved organic carbon (COD) and dissolved iron (FeD)) at regional $(R)$ and local $(L)$ scale. Percentages above standard deviation bars are variation coefficient values.

una parte de la producción de proteínas a la acumulación de biomasa (para asegurar así su supervivencia) sin inducir la división celular (Shiah \& Ducklow, 1997). Es decir, la síntesis de proteínas y la división celular pueden estar desacopladas bajo condiciones de limitación extremas (Pulido-Villena \& Reche, 2003). Este hecho podría ser la causa de la gran diferencia entre los rangos de variación de la abundancia y la producción del bacterioplancton. En este tipo de situaciones, el control por los recursos puede reflejarse sobre la variabilidad de la producción del bacterioplancton pero no sobre la abundancia celular. De hecho, en la escala regional de este estudio, la concentración de PT parece ejercer un claro control sobre la PB pero no sobre la AB (Tabla 3). El FeD explicó un porcentaje muy bajo de la variabilidad de la PB y, al aplicar la corrección de Bonferroni, no se puede descartar la posibilidad de una correlación debida exclusivamente al azar.

Una correlación positiva entre la $\mathrm{AB}$ y la $\mathrm{PB}$ es considerada indicativa de un control del bac- terioplancton por los recursos (Cole et al., 1988; Billen et al., 1990). En este estudio, sin embargo, no se observó esta correlación. La figura 3 muestra la $\mathrm{AB}$ y la $\mathrm{PB}$ en este estudio (los cuadrados corresponden a la escala local y los asteriscos a la escala regional) y la recta de regresión obtenida por Cole et al., 1988 entre la abundancia y producción bacterianas en numerosos sistemas tanto marinos como continentales. Comparando nuestros resultados con los de estos autores, se observa, por un lado, una PB menor de la esperada según los valores de la $\mathrm{AB}, \mathrm{y}$, por otro lado, una elevada dispersión de nuestros datos de $\mathrm{PB}$, especialmente a escala regional. Actualmente, existen evidencias de que una fracción importante del bacterioplancton no es activa metabólicamente (del Giorgio \& Scarborough, 1995; Sondergaard \& Danielsen, 2001). Factores como una baja disponibilidad de nutrientes o condiciones físicas extremas pueden controlar la proporción de bacterias activas en un sistema acuático. La biota de lagunas de Sierra Nevada está sometida a un 


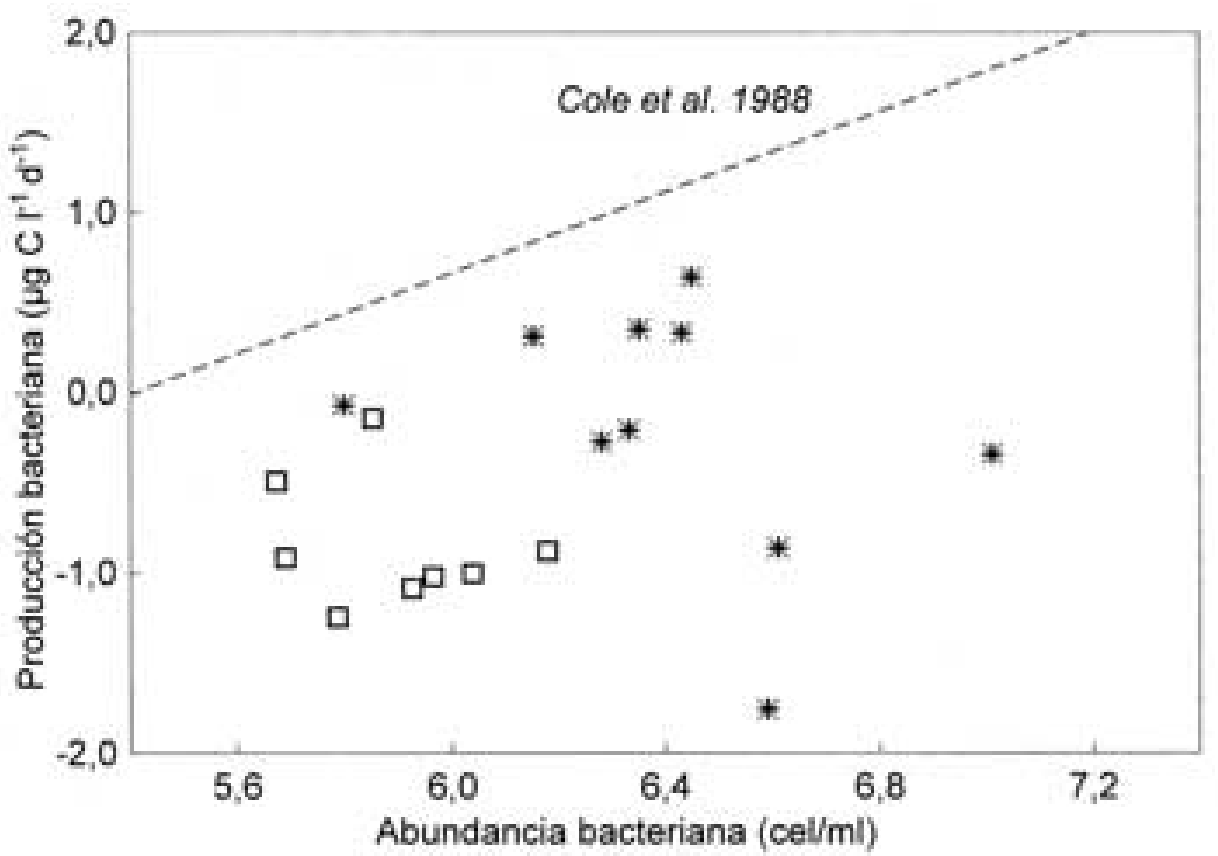

Figura 3. Comparación de la producción bacteriana $(\mathrm{PB})$ y abundancia bacteriana $(\mathrm{AB})$ a escala regional (asteriscos) y local (cuadrados) con la relación entre estos descriptores obtenida por Cole et al. 1988. Todas las variables están transformadas logarítmicamente. Comparison of bacterial production (PB) and bacterial abundance (AB) at regional (stars) and local scale (squares) with the relationship between these descriptors obtained by Cole et al. 1988. All variables are log-transformed.

fuerte estrés físico debido a las bajas temperaturas y la elevada radiación ultravioleta incidente. Es posible, por lo tanto, que en estas lagunas exista una elevada proporción de bacterias inactivas y que la PB se deba exclusivamente a una fracción de las bacterias enumeradas, lo que originaría que los valores de PB observados en este estudio sean menores de lo esperado. La dispersión de los valores de $\mathrm{PB}$ respecto a los de $\mathrm{AB}$ a escala regional apoyaría la hipótesis de que, en estos sistemas, los mecanismos de control relacionados con la disponibilidad de recursos actúan sobre la producción del bacterioplancton y no sobre la abundancia.

A escala regional, la diversidad en las características de las diferentes cuencas de captación (presencia de borreguiles, de arroyos, etc.) puede determinar la variabilidad en la disponibilidad de recursos. El paso de esta escala a una local implica la desaparición de esta diversidad, por lo que los mecanismos de control del bacterioplancton pueden variar. En efecto, como consecuencia de este cambio de escala, se observó una menor variabilidad en los valores de COD y PT. Las características de la cuenca de captación de la laguna de La Caldera (terreno rocoso y ausencia de arroyos) hacen que esta laguna no reciba aportes por escorrentía de nutrientes ni minerales ni orgánicos. Esto supone que, a lo largo del período libre de hielo, no se produzcan grandes variaciones en la concentración de PT y COD. El rango de variación de FeD, por el contrario, fue similar a escala regional y a escala local. Esto se debe, probablemente, a que las variaciones de este parámetro dependen menos de las características de la cuenca y más de la química de la propia laguna. La menor variabilidad en la disponibilidad de PT y COD a escala local podría explicar la reducción de los rangos de variación de los descriptores del bacterio- 
plancton (AB y $\mathrm{PB})$ a esta escala. A pesar de que a escala regional la $\mathrm{PB}$ parece estar controlada por la concentración de PT, esta dependencia no se mantuvo a escala local. Esto podría deberse a que la variabilidad de la concentración de PT a lo largo del período libre de hielo es insuficiente para explicar las variaciones de la PB. Varios trabajos previos han sugerido que las variaciones temporales del bacterioplancton dentro de un mismo sistema están más controladas por la temperatura que por los recursos (Shiah \& Ducklow, 1995; Gurung \& Urabe, 1999). En las lagunas de Sierra Nevada suelen producirse notables variaciones de temperatura por lo que es posible que a esta escala este factor controle la actividad bacteriana. Desafortunadamente, en este estudio no se realizaron medidas de temperatura, ya que estuvo centrado en los mecanismos de control relacionados con la disponibilidad de recursos.

Los resultados de este estudio apuntan a que no todos los patrones de variación del bacterioplancton se mantienen a las diferentes escalas. El paso de una escala regional a una escala local implica cambios en los rangos de variación de ciertos mecanismos de control y, en consecuencia, los patrones observados a escala regional pueden desaparecer a escala local. Además, estos patrones son variables dependiendo del descriptor del bacterioplancton seleccionado. Estos resultados resaltan la necesidad de conocer qué mecanismos de control se mantienen de unas escalas a otras y con qué descriptores del bacterioplancton para poder extrapolar patrones entre diferentes escalas.

\section{AGRADECIMIENTOS}

Agradecemos a E.O. Casamayor, S. Belloch, F. Medialdea, P. Navarro y F. Perfectti su colaboración en el campo y en el laboratorio. El Dr. R. Sommaruga realizó amablemente todos los análisis de COD. Este estudio estuvo financiado por el proyecto CICYT AMB99-0541 y una beca FPI del MCYT concedida a E. Pulido-Villena.

\section{REFERENCIAS}

AZAM, F., T. FENCHEL, J. G. FIELD, J. S. GREY, L. A. MEYER-REIL \& F. THINGSTAD F. 1983. The ecological role of water-column microbes in the sea. Mar. Ecol. Prog. Ser., 10: 257-263.

BARON, J., D. MCKNIGHT \& A. S. DENNING. 1991. Sources of dissolved and particulate organic material in Loch Vale Watershed, Rocky Mountain National Park, Colorado, USA. Biogeochem., 15: 89-110.

BENNER, R. \& M. STROM. 1993. A critical evaluation of the analytic blank associated with DOC measurements by high-temperature catalytic oxidation. Mar. Chem., 41: 153-160.

BILLEN, G., P. SERVAIS \& S. BECQUEVORT. 1990. Dynamics of bacterioplankton in oligotrophic and eutrophic aquatic environments: bottomup or top-down control? Arch. Hydrobiol. Beih., 207: 37-42.

CALDWELL, M. M., R. ROBBERECHT \& W. D. BILLINGS. 1980. A steep latitudinal gradient of solar ultraviolet-B radiation in the artic-alpine zone. Ecology, 61: 600-611.

CHURCH, M. J., D. A. HUTCHINS \& H. W. DUCKLOW. 2000. Limitation of bacterial growth by dissolved organic matter and iron in the southern ocean. Appl. Environ. Microbiol., 66: 455-466.

COLE, J. J., S. FINDLAY \& M. L. PACE. 1988. Bacterial production in fresh and saltwater ecosystems: a cross-system overview. Mar. Ecol. Prog. Ser., 43: 1-10.

COLE, J. J. 1999. Aquatic microbiology for ecosystem scientists: new and recycled paradigms in ecological microbiology. Ecosystems, 2: 215-225.

CURRIE, D. J. 1990. Large-scale variability and interactions among phytoplankton, bacterioplankton, and phosphorous. Limnol. Oceanogr., 35: 1437-1455.

DEL GIORGIO, P. A. \& G. SCARBOROUGH. 1995. Increase in the proportion of metabolically active bacteria along gradients of enrichments in freshwater and marine plankton: implications for estimates of bacterial growth and production rates. J. Plank. Res., 17: 1905-1924.

DUCKLOW, H. W. 1992. Factors regulating bottomup control of bacteria biomass in open ocean plankton communities. Arch. Hydrobiol. Beih., 37: 207-217.

FELIP, M., M. L. PACE \& J. J. COLE. 1996. Regulation of planktonic bacteria growth rates- 
the effects of temperature and resources. Microb. Ecol., 31: 15-28.

FUHRMAN, J. A., \& C. A. SUTTLE. 1993. Viruses in marine planktonic systems. Oceanography, 6: 51-63.

GASOL, J. M. \& C. M. DUARTE. 2000. Comparative analyses in aquatic microbial ecology: how far do they go? FEMS Microbiol. Ecol., 31: 99-106.

GOLDMAN, J. C., D. A. CARON \& M. R. DENNETT. 1987. Regulation of gross growth efficiency and ammonium regeneration in bacteria by substrate C:N ratio. Limnol. Oceanogr., 32: 1239-1252.

GURUNG, T. B., \& J. URABE. 1999. Temporal and vertical difference in factors limiting growth rate of heterotrophic bacteria in lake Biwa. Microb. Ecol., 38: 136-145.

HINDER, B., I. BAUR, K. HANSELMANN \& F. SCHANZ. 1999. Microbial foodweb in an oligotrophic high mountain lake (Jöri Lake III, Switzerland). J. Limnol., 58: 162-168.

HUTCHINSON, G. E. 1953. The concept of pattern in ecology. Proceedings of the Natural Academy of Sciences (USA), 105:1-12.

KIRCHMAN, D. L. 1990. Limitation of bacterial growth by dissolved organic matter in the subartic Pacific. Mar. Ecol. Prog. Ser., 62: 47-54.

KIRCHMAN, D. L. 1994. The uptake of inorganic nutrients by heterotrophic bacteria, Microb. Ecol., 28: 255-271.

KIRCHMAN, D. L., B. MEON, M. T. COTTRELL \& D. A. HUTCHINS. 2000. Carbon versus iron limitation of bacterial growth in the california upwelling regime. Limnol. Oceanogr., 45: 1681-1688.

LEE, S. \& J. FUHRMAN. 1987. Relationships between biovolumen and biomass of naturally derived marine bacterioplankton. Appl. Environ. Microbiol., 53: 1298-1303.

LEVIN, S. A. 1992. The problem of pattern and scale in ecology. Ecology, 73: 1943-1967.

MCMANUS, G. B. \& J. A. FUHRMAN. 1988. Control of marine bacterioplankton populations: measurement and significance of grazing. Hydrobiologia, 159: 51-62.

MORALES-BAQUERO, R., P. CARRILLO, I. RECHE \& P. SANCHEZ-CASTILLO. 1999. Nitrogen-phosphorus relationship in high mountain lakes: effects of the size of catchment basins. Can. J. Fish. Aquat. Sci., 56: 1809-1817.

MORRIS, D. P. \& W. M. LEWIS Jr. 1992. Nutrient limitation of bacterioplankton growth in Lake
Dillon, Colorado. Limnol. Oceanogr., 37: 11791192.

MURPHY, J. \& J. P. RILEY. 1962. A modified single solution methods for the determination of phosphate in natural waters. Annal. Chim. Acta., 27: 31-36.

NÜRNBERG， G. K. \& M. SHAW. 1999. Productivity of clear and humic lakes: nutrients, phytoplankton, bacteria. Hydrobiologia, 382: 97112.

PACE, M. L. \& J. J. COLE. 1994. Comparative and experimental approaches to top-down and bottom-up regulation of bacteria. Microb. Ecol., 28: 181-193.

PORTER, K. G. \& L. S. FEIG. 1980. The use of DAPI for identifying and counting aquatic microflora. Limnol. Oceanogr., 25: 943-948.

PULIDO-VILLENA, E. \& I. RECHE. 2003. Exploring bacterioplankton growth and protein synthesis to determinate conversion factors across a gradient of dissolved organic matter. Microb. Ecol., 46 (1): 33-42.

RECHE, I., A. PUGNETTI, L. CRUZ-PIZARRO \& P. CARRILLO. 1996. Relationship between bacteria and phytoplankton in a high mountain lake: Importance of the organic carbon released by pelagic algae for bacterioplankton. Arch. Hydrobiol. 48: 31-38.

RECHE, I., P. CARRILLO \& L. CRUZ-PIZARRO. 1997. Influence of metazooplankton on interactions of bacteria and phytoplankton in an oligotrophic lake. J. Plank. Res., 19: 631-646.

RECHE, I., M. L. PACE \& J. J. COLE. 1998. Interactions of photobleaching and inorganic nutrients in determining bacterial growth on colored dissolved organic carbon. Microb. Ecol., 36: 270-280.

RECHE, I., E. PULIDO-VILLENA, J. M. CONDEPORCUNA \& P. CARRILLO. 2001. Photoreactivity of dissolved organic matter from high mountain lakes of Sierra Nevada, Spain. Artic, Antartic and Alpine Research, 33: 426-434.

SANDERS, R. W. K. G. PORTER, S. J. BENNET \& A. E. DEBIASE. 1992. Seasonal patterns of bacterivory by flagellates, ciliates, rotifers, and cladocerans in a freshwater planktonic community. Limnol. Oceanogr., 34: 673-684.

SHIAH, F. K. \& H. W. DUCKLOW. 1994. Temperature regulation of heterotrophic bacterioplankton abundance, production, and specific growth rate in Chesapeake Bay. Limnol. Oceanogr., 39: 1243-1258. 
SHIAH, F. K. \& H. W. DUCKLOW. 1995. Regulation of bacterial abundance and production by substrate supply and bacterivory: a mesocosm study. Microb. Ecol., 30: 239-255.

SHIAH, F. K. \& H. W. DUCKLOW. 1997. Bacterioplankton growth responses to temperature and chlorophyll variations in estuaries measured by thymidine: leucine incorporation ratio. Aquat. Microb. Ecol., 13: 151-159.

SMITH, D. C. \& F. AZAM. 1992. A simple, economical method for measuring bacterial protein synthesis rates in seawater using $3 \mathrm{H}$-leucine. Mar. Microb. Food Webs, 6: 107-114.

SOMMARUGA, R., I. OBERNOSTERER, G. J. HERNDL \& R. PSENNER. 1997. Inhibitory effect of solar radiation on thymidine and leucine incorporation by freshwater and marine bacterioplankton. Appl. Environ. Microb., 63: 4178-4184.

SOMMARUGA, R., R. PSENNER, E. SCHAFFERER, K. A. KOINIG \& S. SOMMARUGAWÖGRATH. 1999. Dissolved organic carbon concentration and phytoplankton biomass in high mountain lakes of the Austrian alps: potential effects of climatic warming on UV underwater attenuation. Arctic, Antarctic, and Alpine Research, 31: 247-254.
SOMMARUGA, R. 2001. The role of solar UV radiation in the ecology of alpine lakes. $J$. Photochem. Biol., 62: 35-42.

SØNDERGAARD, M. \& M. DENIELSEN. 2001. Active bacteria (CTC+) in temperate lakes: temporal and cross-system variations. J. Plank. Res., 23: 1195-1206.

TORTELL, P. D., M. T. MALDONADO \& N. M. PRICE. 1996. The role of heterotrophic bacteria in iron-limited ocean ecosystems. Nature, 383: 330-332.

VADSTEIN, O., Y. OLSEN \& H. REINERSTEN. 1993. The role of planktonic bacteria in phosphorous cycling in lakes-sink and link. Limnol. Oceanogr., 38 (1993) 1539-1544.

WHITE, P.A., J. KALFF, J. B. RASMUSSEN \& J. M. GASOL. 1991. The effect of temperature and algal biomass on bacterial production and specific growth rate in freshwater and marine habitats. Microb. Ecol., 21: 99-118.

WILLE, A., B. SONNTAG, B. SATTLER \& R. PSENNER. 1999. Abundance, biomass and size estructure of the microbial assemablage in the high mountain lake Gosseköllesee (Tyrol, Austria) during the ice-free period. J. Limnol., 58: 117126. 